
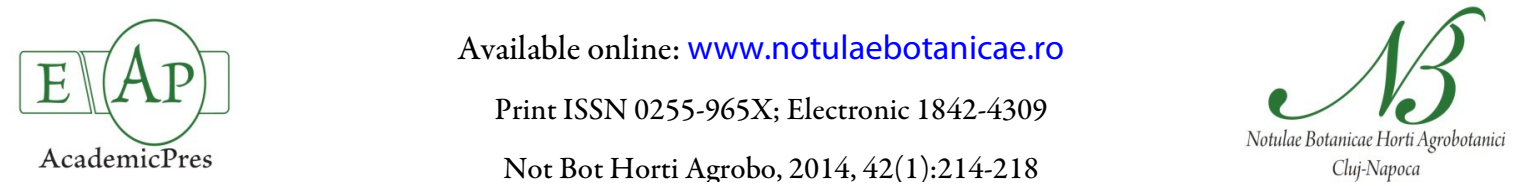

\title{
Evaluation of Drought Tolerance in Safflower Genotypes Based on Drought Tolerance Indices
}

\author{
Marouf KHALILI ${ }^{1}$, Alireza POUR-ABOUGHADAREH ${ }^{2 *}$, \\ Mohammad Reza NAGHAVI ${ }^{3}$, Esmail MOHAMMAD-AMINI ${ }^{4}$ \\ ${ }^{1}$ University of Payame Noor, Department of Agriculture, PO BOX 19395-3697, Tehran, Iran; ma_khalili@yahoo.com \\ ${ }^{2}$ Imam Khomeini International University, Faculty of Engineering and Technology, Department of Plant Breeding and Production, Qazvin, \\ Iran;s926198001@edu.ikiu.ac.ir (*correspondingauthor) \\ ${ }^{3}$ University of Payame Noor, Department of Agriculture, PO BOX 19395-3697,Tehran,Iran;mr_naghavi@ymail.com \\ ${ }^{4}$ University of Tabriz, Faculty of Agriculture, Department of Biotechnology and Plant Breeding, Tabriz, Iran; e.amini21@yahoo.com
}

\begin{abstract}
Among the different environmental stresses, drought is the constraint that induces a highly negative effect on crop production. In order to identify drought tolerant genotypes in safflower, an experiment was conducted in a randomized complete block design with three replications under rainfed and irrigated conditions during 2011-2012 cropping season at Agricultural and Natural Resources Research Center of West Azerbaijan, Iran. Seven drought resistance indices including Stress Tolerance Index (STI), Tolerance Index (TOL), Stress Susceptibility index (SSI), Mean Productivity (MP), Geometric Mean Productivity (GMP), Yield Index (YI) and Yield Stability Index (YSI) were calculated for each genotype based on grain yield under stress and normal conditions. Analysis of variance showed significant difference among genotypes in the terms of grain yield under rainfed and irrigated conditions. Result of correlation analysis between grain yield in both conditions and calculated drought resistance indices revealed that STI, MP, GMP and YI were the best indices for identifying high yielding genotypes in both conditions (drought tolerant genotypes). Gabriel Biplot Multivariate chart showed that 'Syrian', 'PI-537530' and 'PI-537636-S' genotypes relatively identified as drought tolerant and 'Hartman', 'Gila', 'PI-537636, 'PI-537598', 'LRV-51-51' and 'Yenice' genotypes identified as susceptible genotypes. Cluster analysis based on grain yield and drought tolerance indices classified the genotypes into four clusters, therefore this result was consistence with results of biplot analysis.
\end{abstract}

Keywords: Biplot, drought stress, grain yield, safflower, tolerance indices

\section{Introduction}

Safflower (Carthamus tinctorius L.) is a member of the family Compositae or Asteraceae, cultivated mainly for its seed, which is used as edible oil and as birdseed (Dordas and Sioulas, 2008; Istanbulluoglu, 2009). This plant is native to the Middle East and it's resistant to saline conditions and to drought stresses (Bassil and Kaffka, 2002). All the alive and non-alive stresses are the most factors to reducing production nonetheless; drought stress is the most important factor limiting crops production in agricultural systems in arid and semi-arid regions (Mollasadeghi et al., 2011). In general, of 18.5 million hectares of agricultural lands, 6.2 million hectares (33.5\%) is devoted to dry cultivation, and about 1.2 million/ha of lands under dry cultivation, more than $400(\mathrm{~mm})$ rainfall will receive (Mohammadi et al., 2006). Thus, in these areas loss of yield is the main concern of plant breeders. Breeding for drought resistance is difficult by the lack of fast, reproducible screening techniques and the inability to routinely create defined and repeatable water stress conditions when a large amount of genotypes are to be evaluated efficiently (Ramirez and Kelly, 1998). Several indices have been utilized to evaluate genotypes for drought tolerance based on grain yield such as geometric mean productivity (Fernandez, 1992), mean productivity (Rosielle and Hamblin, 1981), stress susceptibility index (Fischer and Maurer, 1978), stress tolerance index (Fernandez, 1992), yield index (Gavuzzi et al., 1997), yield stability index (Bouslama and Schapaugh, 1984) and tolerance (Rosielle and Hamblin, 1981). On the other hand, according to Fernandez (1992) theory genotypes can be categorized into four groups based on their performance in stress and nonstress environments: genotypes which express uniform superiority in both stress and non-stress environments (Group A); genotypes which perform favorably only in non-stress environments (Group B); genotypes which yield relatively well only in stress environments (Group C) and genotypes which perform poorly in both stress and nonstress environments (Group D). The optimal selection criteria should distinguish group A from the other three groups. Therefore, a suitable index (indices) must be able to discriminate the genotype in group A from the other groups. The objectives of the present investigation were to 
(i) identify drought tolerant safflower genotypes under rainfed conditions in the northwest of Iran, (ii) determine the efficiency of tolerance indices to classify genotypes into sensitive and tolerant groups.

\section{Materials and methods}

\section{Experimental design and plant material}

Fifteen genotypes of safflower (Tab. 1) were cultivated in a randomized complete block design with three replications under two different environments (irrigated and rainfed) in 2011-2012, at Agricultural and Natural Resources Research Center of West Azerbaijan, Iran (latitude $36.58^{\circ} \mathrm{N}$, longitude $46.09^{\circ} \mathrm{E}$, Altitude $1310 \mathrm{~m}$ above sea level). Each plot consisted of 6 rows, $5 \mathrm{~m}$ long and spaced $50 \mathrm{~cm}$ apart. Fertilizers were applied prior to sowing at a rate of $80 \mathrm{kgha}^{-1}$ Ammonium Phosphate $\left(\mathrm{NH}_{4} \mathrm{H}_{2} \mathrm{PO}_{4}\right)$ and $65 \mathrm{kgha}^{-1}$ Urea $\left(\mathrm{CO}\left(\mathrm{NH}_{2}\right)_{2}\right)$. Non-stressed plots were irrigated after sowing and subsequent irrigations were carried out after $75 \mathrm{~mm}$ evaporation from class A pan. Weeds were controlled by hand during crop growth and development. At maturity stage after separation of border effects from each plot, grain yield were measured and seven drought tolerance indices such as SSI (Fischer and Maurer, 1978), GMP (Fernandez, 1992), MP (Rosielle and Hamblin, 1981), TOL (Rosielle and Hamblin, 1981), STI (Fernandez, 1992), YI (Gavuzzi et al., 1997), YSI (Bouslama and Schapaugh, 1984) were calculated using the following formula:
(1) $\mathrm{SSI}=(1-(\mathrm{Ys} / \mathrm{Yp})) /(1-(\overline{Y s}) /-(\overline{Y p}))$
(2) $\mathrm{GMP}=\sqrt{Y s \times Y p}$
(3) $\mathrm{MP}=(\mathrm{Ys}+\mathrm{Yp}) / 2$
(4) $\mathrm{TOL}=\mathrm{Yp}-\mathrm{Ys}$
(5) $\mathrm{STI}=\left(\mathrm{Ys}_{\mathrm{X}} \mathrm{Yp}\right) /(\overline{Y p})^{2}$
(6) $\mathrm{YI}=(\mathrm{Ys}) /(\overline{Y s})$
(7) $\mathrm{YSI}=\mathrm{Ys} / \mathrm{Yp}$

Tab. 1. The genotypes used in the experiment

\begin{tabular}{cccccc}
\hline No. & $\begin{array}{c}\text { Genotype } \\
\text { 'PI- } \\
1\end{array}$ & No. & Genotype & No. & Genotype \\
'L89290' & 6 & 'Dincer' & 11 & $\begin{array}{c}\text { 'LRV-51- } \\
51 '\end{array}$ \\
2 & 'CW-4440' & 7 & 'Hartman' & 12 & $\begin{array}{c}\text { 'KINO- } \\
76\end{array}$ \\
3 & 'Syrian' & 8 & 'Gila' & 13 & 'Yenice' \\
4 & 'PI-537530' & 9 & $\begin{array}{c}\text { 'PI- } \\
537636 '\end{array}$ & 14 & $\begin{array}{c}\text { 'PI- } \\
537636-S\end{array}$ \\
5 & 'CH-5' & 10 & $\begin{array}{c}\text { 'PI- } \\
537598\end{array}$ & 15 & 'IL-111' \\
\hline
\end{tabular}

In the above formulas $\mathrm{Ys}, \mathrm{Yp}, \overline{Y s}$ and $\overline{Y p}$ represent yield under stress, yield non-stress for each cultivar, yield mean in stress and non-stress conditions for all cultivars, respectively. The data were analyzed using SPSS ver.16 software for analysis of variance and cluster analysis of genotypes based on Square Euclidean distance and Ward method. The principle component analysis (PCA) and biplot display were also used to identify tolerant and high yielding genotypes using MINITAB ver.16 software.

\section{Results and discussion}

Results of analysis of variance for grain yield over both conditions, showed that difference significant between genotypes (Tab. 2). In the both conditions highest values for grain yield belonged to genotypes No. 3, 4 and 15. On the other hand, genotypes No. 7,9 and 11 had lowest grain yield in stress condition, however the lowest grain yield under non-stress condition belonged to genotypes No. 8, 11 and 14 (Tab. 3). The drought tolerance indices for genotype based on grain yield in non-stress and stress conditions are presented in Tab. 3. According to TOL genotypes No. 8, 13 and 14 exhibited the lowest value. Also, based on SSI the lowest value belonged to genotype No. 3, 4 and 14, thus these genotypes were found as drought tolerance. Based on STI and GMP values, genotypes No. 6, 9, 12, 14 and 19 identified as drought tolerant genotypes. In the case of the indices MP and GMP genotypes No.8 followed by No. 9, 10 and 11 were found to be drought tolerant genotypes. Also, STI, YI and YSI indices selected genotypes No. 3, 4 and 15 as the most relatively tolerant genotypes. Albeit selection based on a combination of indices may provide a more useful criterion for improving drought tolerance, however correlation analysis between grain yield and drought tolerance indices can be a good criterion for screening the best genotypes and indices. Thus, a suitable index must significantly correlated with grain yield under both the conditions (Mitra, 2001). Results of correlation analysis between grain yields in both conditions with drought tolerance indices showed that STI, GMP, MP and YI had positive and significant correlations with Yp and Ys. Therefore these indices were able to discriminate group A genotypes from other genotypes. A significant negatively correlation was observed between SSI and grain yield under stress condition. Hence, as for the positive correlation between SSI and yield under non-stress (Yp) condition and a negative correlation between SSI and yield under stress condition suggested that selection based on SSI will result in increased yield under non-stress conditions (Sio-Se Mardeh et al., 2006). The YSI was positively correlated with Ys and had negative correlation with Yp, so highest values of YSI belonged to genotypes that exhibited least yield in irrigated conditions, but exhibited high yield under rain-fed conditions. This result were consistent with Sio-Se Mardeh et al. (2006) and Zebarjadi et al. (2012). Naghavi et al. (2013) showed that correlation between MP, GMP, Ys and Yp was positive. In the study conducted by Ilker et al. (2011) STI, MP and GMP were positively significant correlated with grain yield over both conditions, whereas of the three primary grain yield components, with either positive or negative correlation between grain yield and plant height. Khalili et al. (2012) reported that GMP, MP, and STI were significantly and positively correlated with grain yield in non-stress and stress conditions.

To better understand the relationships, similarities and dissimilarities among the indicators of drought tolerance, biplot displayed based on principal component analysis (PCA). This analysis revealed that the two first PCA explained $99.7 \%$ of total variation. The first PCA explained $62.51 \%$ of the variation with Yp, Ys, MP, GMP, YI and STI. Hence, this component can be named as the yield stability and tolerance to drought. The genotypes with 
216

higher values of $\mathrm{PC} 1$ are expected to be drought tolerant and high yielding genotypes. The second PCA explained $37.18 \%$ of the total variability and had high positive correlation with Yp, TOL and SSI. Therefore, the second component can be named as a stress susceptibility and stability yield. Also, the genotypes No. 3, 4 and 14 had higher values for PC1 and low values for PC2 thus, these genotypes identified as drought tolerance. Genotypes No. 1, 2, 5, 6 and 12 for the reason that placed among of PC1 and PC2 identified as semi tolerance to drought stress. In spite of the fact that genotypes No. 15 had high grain yield over both conditions but this genotype were sensitive to drought stress in respect of their high values for both PC1 and PC2. Genotypes No. 7, 8, 9, 10, 11 and 13 were susceptible to drought stress and had low grain yield performance, because

Tab. 2. Analysis of variance for grain yield $\left(\mathrm{kg} \mathrm{h}^{-1}\right)$ in stress and non-stress conditions

\begin{tabular}{|c|c|c|c|}
\hline \multirow{2}{*}{$\begin{array}{l}\text { Source of } \\
\text { variation }\end{array}$} & \multirow{2}{*}{ d.f. } & \multicolumn{2}{|c|}{ Mean of squares } \\
\hline & & Irrigated & Rainfed \\
\hline Replication & 2 & 133763.89 & $268763.89^{* *}$ \\
\hline Genotype & 14 & $93240.08^{*}$ & $54805.56^{*}$ \\
\hline Error & 28 & 48689.48 & 25609.13 \\
\hline \multicolumn{2}{|c|}{ CV\% } & 11.34 & 14.22 \\
\hline
\end{tabular}

this genotypes had lower amounts of both PC1 and PC2 in comparison to other genotypes. Finally, our results were consistent with those reported by Golabadi et al. (2006) Kaya et al. (2002), Talebi et al. (2011) and Zebarjadi et al. (2012).

The result of cluster analysis for studied genotypes has been presented in Fig. 2. The 15 safflower genotypes based on grain yield and STI, MP, GMP and YI were classified in four clusters. Genotypes No. 7, 8, 9, 10, 11 and 13 classified in the first cluster. In this cluster, all genotypes had high SSI, thus they were susceptible to drought and only suitable for irrigated conditions. The second cluster comprising genotypes No. 1, 2, 5, 6 and 12. These genotypes had mean indicators values therefore, they identified as semi-tolerance or semi-sensitive genotypes. The third cluster consists of genotypes No. 3, 4 and 14. These genotypes had high STI, MP, GMP, YI and YSI values, thus they considered to be the most desirable genotypes for both growth conditions. Finally, genotype No. 15 belonged to fifth cluster and this genotype have high grain yield in both conditions. In general, these results were agreement with results obtained from biplot analysis. Cluster analysis has been generally utilized for description of variation between genotypes and grouping based on drought tolerance indices (Golabadi $e t$ al., 2006; Malek Shahi et al., 2009; Khalili et al., 2012; Naghavi et al., 2013).

Tab. 3. Drought tolerance indices and comparison of grain yield based on Duncan method in non-stress and stress conditions

\begin{tabular}{cccccccccc}
\hline No. & $\mathrm{Yp}\left(\mathrm{kg} \mathrm{h}^{-1)}\right.$ & $\mathrm{Ys}_{\mathrm{sg} \mathrm{h}} \mathrm{kg}^{-1)}$ & SSI & STI & TOL & MP & GMP & YSI & YI \\
\hline 1 & $1991.67 \mathrm{ab}$ & $1150 \mathrm{abcd}$ & 1.00 & 0.60 & 841.67 & 1570.83 & 1513.41 & 0.57 & 1.02 \\
2 & $1983.33 \mathrm{ab}$ & $1075 \mathrm{bcd}$ & 1.08 & 0.56 & 908.33 & 1529.16 & 1460.16 & 0.54 & 0.95 \\
3 & $2050.00 \mathrm{ab}$ & $1300 \mathrm{abc}$ & 0.86 & 0.70 & 750.00 & 1675.00 & 1632.48 & 0.63 & 1.15 \\
4 & $2116.67 \mathrm{ab}$ & $1283.33 \mathrm{abcd}$ & 0.93 & 0.71 & 833.34 & 1700.00 & 1648.14 & 0.60 & 1.14 \\
5 & $2041.67 \mathrm{~b}$ & $1050 \mathrm{bcd}$ & 1.15 & 0.56 & 991.67 & 1545.83 & 1464.15 & 0.51 & 0.93 \\
6 & $2050.00 \mathrm{~b}$ & $1108.33 \mathrm{abcd}$ & 1.09 & 0.60 & 941.67 & 1579.16 & 1507.34 & 0.54 & 0.98 \\
7 & $1866.67 \mathrm{~b}$ & $1025 \mathrm{bcd}$ & 1.07 & 0.50 & 841.67 & 1445.83 & 1383.23 & 0.55 & 0.91 \\
8 & $1783.33 \mathrm{~b}$ & $1058.33 \mathrm{~cd}$ & 0.96 & 0.49 & 725.00 & 1420.83 & 1373.81 & 0.59 & 0.94 \\
9 & $1850.00 \mathrm{~b}$ & $991.67 \mathrm{~cd}$ & 1.10 & 0.48 & 858.33 & 1420.83 & 1354.46 & 0.53 & 0.88 \\
10 & $1808.33 \mathrm{~b}$ & $1033.33 \mathrm{~cd}$ & 1.01 & 0.49 & 775.00 & 1420.83 & 1366.96 & 0.57 & 0.92 \\
11 & $1733.33 \mathrm{~b}$ & $983.33 \mathrm{~d}$ & 1.02 & 0.45 & 750.00 & 1358.33 & 1305.54 & 0.56 & 0.87 \\
12 & $1966.67 \mathrm{~b}$ & $1025.1 \mathrm{dc}$ & 1.13 & 0.53 & 941.57 & 1495.88 & 1419.87 & 0.52 & 0.91 \\
13 & $1791.67 \mathrm{~b}$ & $1066.67 \mathrm{bcd}$ & 0.96 & 0.50 & 725.00 & 1429.17 & 1382.43 & 0.59 & 0.94 \\
14 & $1758.33 \mathrm{~b}$ & $1358.33 \mathrm{ab}$ & 0.54 & 0.63 & 400.00 & 1558.33 & 1545.44 & 0.77 & 1.20 \\
15 & $2400.00 \mathrm{a}$ & $1375 \mathrm{a}$ & 1.01 & 0.87 & 1025.0 & 1887.50 & 1816.59 & 0.57 & 1.22 \\
\hline
\end{tabular}

${ }^{*}$ For each trait, means with the same letters have no significant difference at $5 \%$ level of probability. Yp: Yield in non-stress condition; Ys: Yield in stress condition; SSI: Stress Susceptibility Index; STI: Stress Tolerance Index; TOL: Tolerance Index; MP: Mean Productivity; GMP: Geometric Mean Productivity; YSI: Yield Stability Index and YI: Yield Index. For Genotypes name (No.) see Tab. 1.

Tab. 4. Correlation coefficients between drought tolerance indices and grain yield in irrigated and rainfed conditions

\begin{tabular}{|c|c|c|c|c|c|c|c|c|c|}
\hline Trait & $Y p$ & Ys & TOL & MP & GMP & SSI & STI & YSI & YI \\
\hline $\mathrm{Yp}$ & 1 & & & & & & & & \\
\hline Ys & $0.56^{*}$ & 1 & & & & & & & \\
\hline TOL & $0.66^{* *}$ & -0.24 & 1 & & & & & & \\
\hline MP & $0.91^{* *}$ & $0.84^{* *}$ & 0.31 & 1 & & & & & \\
\hline GMP & $0.85^{* *}$ & $0.91^{* *}$ & 0.19 & $0.99^{* *}$ & 1 & & & & \\
\hline SSI & 0.23 & $-0.67^{* *}$ & $0.87^{* *}$ & -0.17 & -0.29 & 1 & & & \\
\hline STI & $0.86^{* *}$ & $0.90^{* *}$ & 0.19 & $0.99^{* *}$ & $0.99^{* *}$ & -0.28 & 1 & & \\
\hline YSI & -0.23 & $0.67^{* *}$ & $-0.87^{* *}$ & 0.18 & 0.298 & $-1^{* *}$ & 0.28 & 1 & \\
\hline YI & $0.55^{*}$ & $1^{* *}$ & -0.24 & $0.85^{* *}$ & $0.90^{* *}$ & $-0.67^{* *}$ & $0.90^{* *}$ & $0.67^{* *}$ & 1 \\
\hline
\end{tabular}

Ys: Yield in stress condition; Yp: Yield in non-stress condition; SSI: Stress Susceptibility Index; STI: Stress Tolerance Index; TOL: Tolerance Index; MP: Mean Productivity; GMP: Geometric Mean Productivity; YSI: Yield Stability Index and YI: Yield Index. 


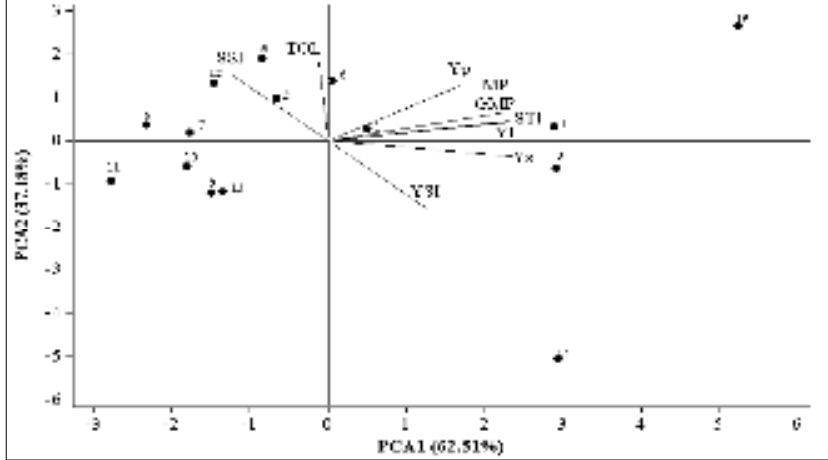

Fig. 1. Biplot for drought tolerance indices in 15 spring safflower genotypes based on first two components. Numbers inside the figure are genotypes number. Ys: Yield in stress condition; Yp: Yield in non-stress condition; SSI: Stress Susceptibility Index; STI: Stress Tolerance Index; TOL: Tolerance Index; MP: Mean Productivity; GMP: Geometric Mean Productivity; YSI: Yield Stability Index and YI: Yield Index.

\section{Conclusions}

Results of present study indicated that STI, MP, GMP and YI are the suitable indices for screening genotypes that produce higher yields in both stress and non-stress conditions (drought tolerant genotypes). Screening drought tolerant genotypes using biplot and cluster analysis discriminated 'Syrian', 'PI-537530' and 'PI-537636-S' genotypes as the most drought tolerant. Therefore they are recommended to be used as parents for improvement of drought tolerance in other cultivars.

\section{References}

Bassil ES, Kaffka SR (2002). Response of safflower (Carthamus tinctorius L.) to saline soils and irrigation. I. Consumptive water use. Agricultural Water Management 54:67-80.

Bouslama M, Schapaugh WT (1984). Stress tolerance in soybeans. Part 1: evaluation of three screening techniques for heat and drought tolerance. Crop Science 24:933-937.

Clarke JM, De-Pauw RM, Townley-Smith TF (1992). Evaluation of methods for quantification of drought tolerance in wheat. Crop Science 32:423-428.

Dordas CA, Sioulas C (2008). Safflower yield, chlorophyll content, photosynthesis, and water use efficiency response to nitrogen fertilization under rainfed conditions. Industrial Crops and Products 27:75-85.

Fernandez GCJ (1992). Effective selection criteria for assessing stress tolerance. Proceedings of the International Symposium on Adaptation of Vegetables and Other Food Crops in Temperature and Water Stress Tolerance. Asian Vegetable Research and Development Centre, Taiwan, 257-270 p.

Fischer RA, Maurer R (1978). Drought resistance in spring wheat cultivars. I. Grain yield responses. Australian Journal of Agricultural Research 29:897-912.

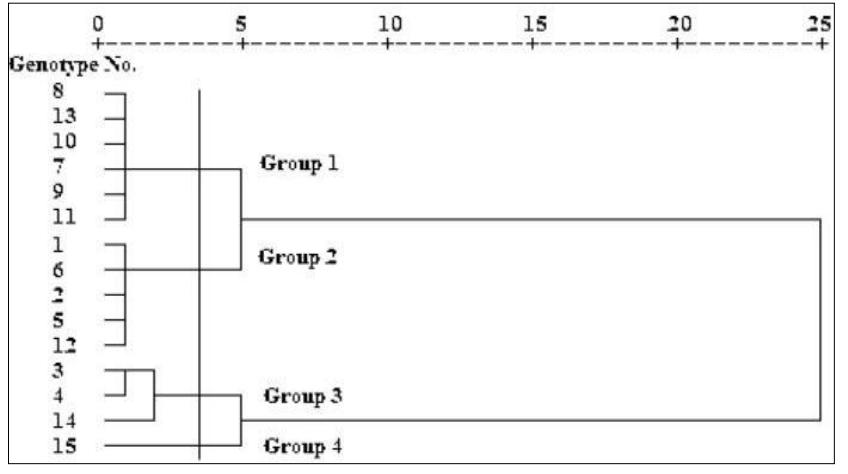

Fig. 2. Dendrogram of cluster analysis of spring safflower genotypes based on yield in non-stress condition (Yp), yield in stress condition (Ys), Mean Productivity (MP), Geometric Mean Productivity (GMP), Stress Tolerance Index (STI) and Yield Stability Index (YI) indices using Ward method. Numbers inside the figure are genotypes number.

Gavuzzi P, Rizza F, Palumbo M, Campanile RG, Ricciardi GL, Borghi B (1997). Evaluation of field and laboratory predictors of drought and heat tolerance in winter cereals. Canadian Journal of Plant Science 77:523-531.

Golabadi M, Arzani A, Maibody M (2006). Assessment of drought tolerance in segregating populations in durum wheat. African Journal of Agricultural Research 1(5): 162-171.

Ilker E, Tatar O, Aykut Tonk F, Tosun M (2011). Determination of Tolerance Level of Some Wheat Genotypes to PostAnthesis Drought. Turkish Journal of Field Crops 16(1):5963.

Istanbulluoglu A (2009). Effects of irrigation regimes on yield and water productivity of safflower (Carthamus tinctorius L.) under Mediterranean climatic condition. Agricultural Water Management 96:1792-1798.

Kaya Y, Palta C, Taner S (2002). Additive main effects and multiplicative interactions analysis of yield performances in bread wheat genotypes across environments. Turkish Journal of Agriculture and Forestry 26:275-279.

Khalili M, Naghavi MR, Pour-Aboughadareh AR, Talebzadeh SJ (2012). Evaluating of drought stress tolerance based on selection indices in spring canola cultivars (Brassica napus L.). Journal of Agricultural Science 4(11):78-85.

Malek-Shahi F, Dehghani H, Alizadeh B (2009). Study of drought tolerance indices in some cultivars of winter rapeseed (Brassica napus L.). Journal of Science and Technology of Agriculture and Natural Resources, Water and Soil Science 48:78-89.

Mitra J (2001). Genetics and genetic improvement of drought resistance in crop plants. Current Science 80:758-763.

Mohammadi R, Haghparast R, Aghaei-Sarbarzeh M, Abdollahi A (2006). Evaluation of drought tolerance rate of advanced genotypes of Durum wheat on the basis of physiologic standards and other related indices. Iranian Agriculture Sciences 3(1):561-567. 
218

Mollasadeghi V, Valizadeh M, Shahryariand R, Imani AA (2011). Evaluation of end drought tolerance of 12 wheat genotypes by stress in dices. Middle-East Journal of Scientific Research 7(2):241-247.

Naghavi MR, Pour-Aboughadareh AR, Khalili M (2013). Evaluation of drought tolerance indices for screening some of corn (Zea mays L.) Cultivars under environmental conditions. Notulae Scientia Biologicae 5(3):388-393.

Ramirez-Vallejo P, Kelly JD (1998). Traits related to drought resistance in common bean. Euphytica 99: 127-136.

Rosielle AA, Hamblin J (1981). Theoretical aspects of selection for yield in stress and non-stress environments. Crop Science 21:943-946.
Sio-Se Mardeh A, Ahmadi A, Poustini K, Mohammadi V (2006). Evaluation of drought resistance indices under various environmental conditions. Field Crops Research 98:222-229.

Talebi R, Baghebani N, Karami E, Ensafi MH (2011). Defining Selection Indices for Drought Tolerance in Chickpea under Terminal Drought Stresses. Journal of Applied Biological Sciences 5(3):33-38.

Zebarjadi A, Mirany T, Kahrizi D, Ghobadi M, Nikoseresht R (2012). Assessment of drought tolerance in some bread wheat genotypes using drought resistance indices. Biharean Biologist $6(2): 94-98$. 